\title{
The pathogenesis of renal injury and treatment in light chain deposition disease
}

\author{
Qi Wang ${ }^{1,2+}$, Fang Jiang ${ }^{3+}$ and Gaosi Xu ${ }^{1 *}$
}

\begin{abstract}
Light chain deposition disease (LCDD) is a rare clinical disorder. The deposition of light chain immunoglobulins mainly affects the kidneys, which have different characteristics than other tissues. To date, the therapeutic approach for the treatment of LCDD has no evidence-based consensus, and clinical experience of reported cases guides current disease management strategies. The present systematic review investigates and summarizes the pathological mechanisms of renal injury and the subsequent treatments for LCDD.
\end{abstract}

Keywords: Light chain deposition disease, Renal injury, Biopsy, Chemotherapy, Treatment

\section{Background}

Monoclonal immunoglobulin deposition disease (MIDD) is a multi-system disease characterized by the deposition of monoclonal Ig molecules in various organs $[1,2]$. Light chain deposition disease (LCDD) is the most common form of MIDD diagnosed, and it is a systemic disease. Many organs are affected by the deposition of monotype immunoglobulin light chain (LCs), but the kidneys are always affected [3]. Primary plasma cell abnormalities or other lymphoproliferative diseases are usually associated with the pathology of LCDD. However, morphological renal lesions (i.e., the presence of nodular sclerosis and the distribution of deposits) do not seem to correlate with patient survival in LCDD [4]. Because free light chains (FLCs) are rapidly cleared from the serum and are largely filtered by the kidneys, this organ is a prominent target for LC deposition and is often damaged. Clinically, LCDD is characterized by prominent mesangial nodules, a thickening of the peripheral basement membrane, and the extensive deposition of monoclonal LCs. Renal involvement in LCDD presents as renal lesions, hypertension, microhematuria, proteinuria and, more rarely, renal tubular acidosis. Extrarenal lesions are present in

\footnotetext{
*Correspondence: gaosixu@163.com

${ }^{\dagger}$ Qi Wang and Fang Jiang contributed equally to this work.

${ }^{1}$ Department of Nephrology, The Second Affiliated Hospital of Nanchang

University, No. 1, Minde Road, Donghu District, Nanchang Zip Code:

330006, People's Republic of China

Full list of author information is available at the end of the article
}

$35 \%$ of patients and can cause clinical symptoms, and extrarenal LC deposition has a clear, independent effect on patient survival [4].

LCDD is relatively rare and it is frequently misdiagnosed as a protein disease. Up to $50 \%$ of patients are diagnosed with LCDD secondary to multiple myeloma or other lymphoproliferative diseases. The diagnosis of LCDD can be made with a kidney biopsy. The characteristic morphological findings in LCDD are nodular glomerulosclerosis and nonfibrillar electron-dense deposits on the glomerular or tubular basement membrane, as seen with electron microscopy (EM). To date, there is no unified standard for the treatment of primary LCDD.

\section{The pathological manifestations of LCDD Light microscopy (LM)}

In total, $30-100 \%$ of LCDD patients in the United States and France are characterized by nodular glomerulosclerosis $[5,6]$. Under LM, LCDD shows the glomeruli with nodular mesangial expansion, a thickening and wrinkling of the glomerular basement membrane (GBM), and glomerular peripheral capillary walls with focal irregular thickening. Periodic acid-Schiff (PAS) staining is positive in LCs. The deposits in LCDD are neither fibrillar nor stained by Congo red. Milder forms of LCDD are characterized by moderately thickened basement membrane and an increased mesangial matrix and cells. Glomerular lesions require ultrastructural examination when not detected by LM. 


\section{Immunofluorescence (IF)}

IF examination of the kidney has been a key step in the diagnosis of LCDD. Along tubular basement membranes, monotypic LCs (mostly $\mathrm{\kappa}$ ) are found in kidney biopsy specimens. The diagnosis of LCDD requires this evaluation. IF can reveal staining of LCs, either kappa or lambda, along the mesangial nodules, peritubular regions, vessels, interstitium, and GBM. However, the staining of IgG, IgA, IgM, and C3 is negative.

\section{Electron microscopy (EM)}

Electron-dense, nonfibrillar, amorphous deposits in the GBM and tubular basement membranes are seen under EM [6]. Subendothelial linear punctate to powdery deposits are distributed in the capillary walls, while podocyte foot processes are largely preserved. EM depicts these deposits as dark granular electron densities. Under EM, dense granular deposits should be present in the mesangial area and subendothelial space without fibrillar structures. However, $8 \%$ of patients with LCDD have 8-20 nm fibrillar structures [7]. The fibrillar structure gradually replaces the normal matrix, leading to the destruction of the glomerular architecture [8-10]. The morphological, immunofluorescence staining and ultrastructural characteristics are summarized in Table 1.

\section{The pathogenesis of renal injury in LCDD}

Glomerular-filtered FLCs are reabsorbed in the mesangium or proximal tubules. Mesangial cells (MCs) secrete extracellular matrix (ECM), mediators and enzymes such as matrix metalloproteinases (MMPs) to support and maintain the glomerulus [11-18]. The increasing deposition of ECM proteins and monotypic LCs results in mesangial nodularity within the glomerulus. MCs are critical in the pathogenesis of glomerulosclerosis.
Figure 1 summarizes the interactions of MCs with glomerulopathic FLCs.

FLCs bind to putative receptors residing in caveolae present on the plasma membrane of MCs to initiate intracellular signalling $[19,20]$. This signalling leads to the overexpression of the receptor [20]. The majority of monoclonal LCs in LCDD are $\kappa$, specifically the VkIV subgroup [2, 21-23]. The complementarity-determining region (CDR) of LCDD-associated FLCs has unusual hydrophobic amino acids (AA) substitutions [24], and $\kappa-L C s$ in LCDD have an exposed b-edge that is part of the antigen binding site in the CDR2 loop, whereas $\lambda$-LCs do not [25]. This exposed edge leads to spontaneous aggregation of the k-LCs into oligomers, which may eventually form granular deposits [25]. The VkIV subgroup, which is frequently overrepresented in LCDD, has a particularly long CDR1 loop [26]. The CDR1 loop may promote conformational changes or the aggregation of the FLCs through its multiple hydrophobic residues. LCDD FLCs inhibit the release of MMP-7 from MCs [27]. MCs in LCDD show a significant decrease in the expression of MMP-7, which degrades tenascin-C [28], resulting in increased ECM.

Ribosomal S6 kinase (RSK) can phosphorylate a variety of transcription factors, including c-fos, promoting nuclear signal transduction [29]. C-fos acts via plateletderived growth factor (PDGF)- $\beta$ to further increase interactions with FLCs [19]. Nuclear factor kappa-lightchain-enhancer of activated B cells (NF- $\mathrm{kB}$ ) and c-fos are induced to migrate to the nucleus by LCDD-associated FLCs [19]. The activation of c-fos results in the transcription of PDGF- $\beta$. PDGF- $\beta$ mediates effects on MCs when exposed to glomerular LCs [30]. PDGF induces human fibroblast cell membrane wrinkling [31]. Previous studies have shown that the activation of the transcription factor NF- $\mathrm{KB}$ plays an important role in interleukin-1

Table 1 Results of renal histopathological examination in patients with LCDD

\begin{tabular}{|c|c|c|c|}
\hline & Light microscopy (LM) & Immuno-fluorescence (IF) & Electron microscopy (EM) \\
\hline Glomerular & $\begin{array}{l}\text { Mild to moderate nodular mesangial } \\
\text { expansion }\end{array}$ & $\begin{array}{l}\text { Linear, either kappa or lambda, LC } \\
\text { restricted staining of glomerular, nega- } \\
\text { tive for lgG, IgA, IgM, and C3 }\end{array}$ & $\begin{array}{l}\text { Dark powdery electron dense deposits } \\
\text { along the inner aspects of glomerular } \\
\text { basement membranes, or nodular } \\
\text { glomerulosclerosis with abundant } \\
\text { powdery to vaguely organized electron } \\
\text { dense deposits in the expanded and } \\
\text { condensed mesangium }\end{array}$ \\
\hline Tubular & $\begin{array}{l}\text { Thickening and wrinkling of the tubular } \\
\text { basement membranes }\end{array}$ & $\begin{array}{l}\text { Monotypic LC (mostly k) fixation along } \\
\text { tubular basement membranes, negative } \\
\text { for } \lg G, \lg A \text {, IgM, and C3 }\end{array}$ & $\begin{array}{l}\text { Linear punctate to powdery deposits } \\
\text { along tubular basement membranes }\end{array}$ \\
\hline The small arterioles & $\begin{array}{l}\text { Focal irregular thickening of the capillary } \\
\text { walls }\end{array}$ & $\begin{array}{l}\text { Strong LC staining along the peritubular } \\
\text { capillary, negative for } \lg G, \lg A \text {, } \lg M \\
\text { and } C 3\end{array}$ & $\begin{array}{l}\text { Diffuse subendothelial linear punctate } \\
\text { to powdery deposits with mostly } \\
\text { preserved the capillary walls }\end{array}$ \\
\hline
\end{tabular}




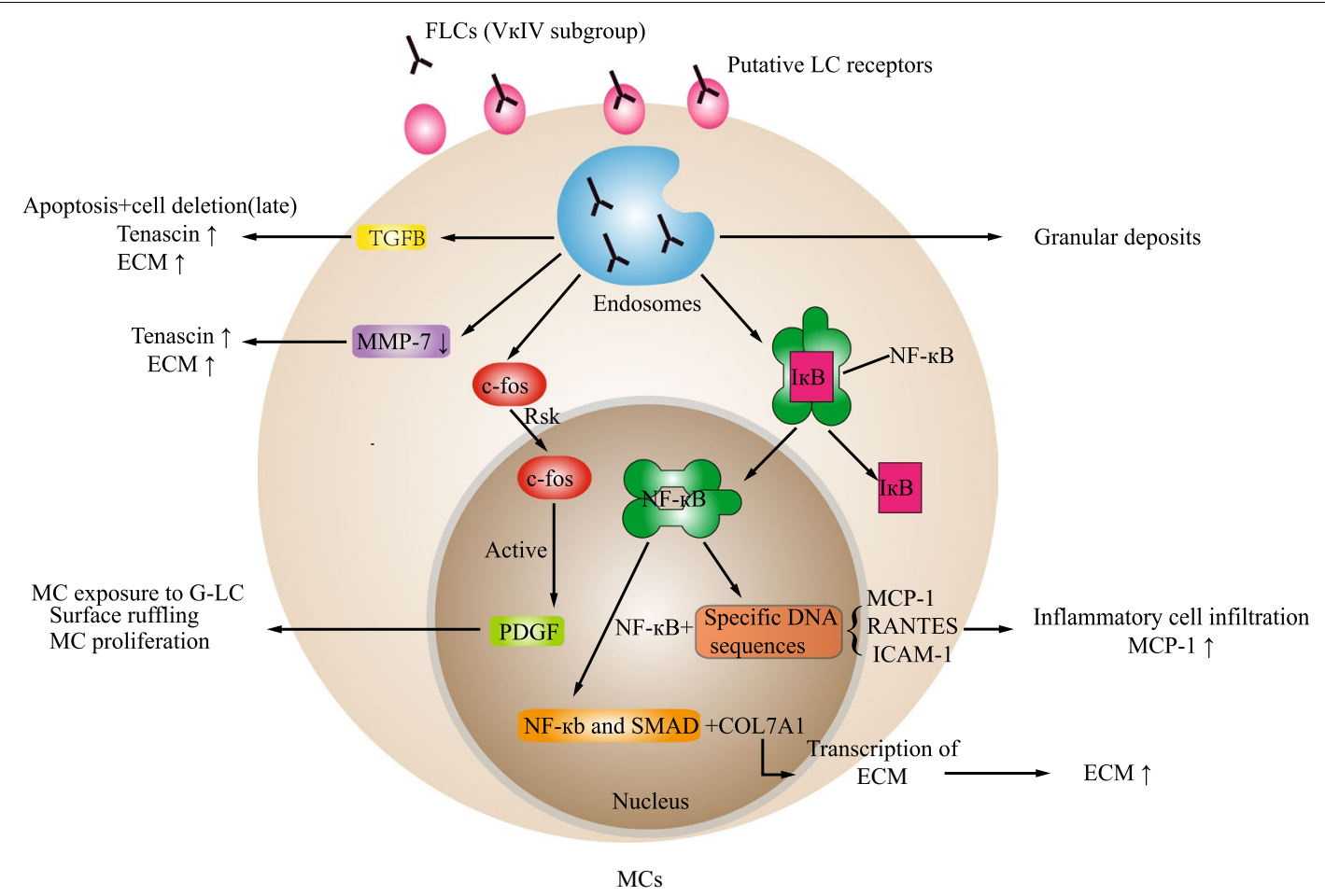

Fig. 1 The interaction between light chain deposition disease (LCDD) free light chain (FLCs) and mesangial cells (MCs): FLCs enter MCs through a putative receptor. LCDD FLCs are processed in endosomes. The processed FLCs are deposited on the membrane of mesangial cells as granular deposits. Meanwhile, transforming growth factor (TGF)- $\beta$ production is increased and matrix metalloproteinase (MMP)-7 is decreased, resulting in an increase in ECM and tenascin. Furthermore, TGF- $\beta$ leads to apoptosis and the late deletion of cells. Nuclear factor kappa-light-chain-enhancer of activated B cells (NF-kB), as a dimer of P50 and p65 subunits, usually exists in the cytoplasm of MCs, binding to its inhibitor protein, IKB. When LCs stimulate MCs, IKB is released from the dimer, resulting in NF-KB migration to the nucleus. NF-KB binds to specific DNA (MCP-1, RANTES, ICAM-1), leading to inflammatory cell infiltration and an increase MCP-1. The functional interaction between NF-KB and SMAD leads to the activation of COL7A1 expression, resulting in an increase in ECM. Ribosomal S6 kinase (RSK) phosphorylates c-fos. Then the activation of c-fos results in the transcription of PDGF- $\beta$. PDGF induces MCs to be exposed to monoclonal LC, and cell surface wrinkling increases the cell surface area and promotes MC early proliferation. LCDD Light chain deposition disease, FLC Free light chain, ECM Extracellular matrix, TGF- $\beta$ Transforming growth factor- $\beta$, MMP-7 Matrix metalloproteinases-7, RSK Ribosomal S6 kinase, NF-KB Nuclear factor kappa-light-chain-enhancer of activated B cells, PDGF Platelet-derived growth factor, MCP Monocyte chemoattractant protein, RANTES Regulated upon activation normal T-expressed and secreted, ICAM-1 Intercellular adhesion molecule-1

(IL-1)-induced monocyte chemoattractant protein-1 (MCP-1) expression [29, 32]. Rovin et al. [33] proposed that phosphotyrosine kinase signalling mechanism could stimulate NF- $\kappa B$, but this is not generally accepted [34]. NF- $\kappa B$ translocates into the nucleus and binds to specific DNA sequences on NF- $\kappa B$ response genes, such as MCP1 , regulated upon activation normal $\mathrm{T}$-expressed and secreted (RANTES), and ICAM-1, resulting in enhanced transcription and generation [19]. Kon and colleagues have shown a functional interaction between NF-kb and SMAD, two early-intermediate transcription factors, to activate COL7A1 expression, an ECM-related gene [35].

When MCs are exposed to FLCs in LCDD, transforming growth factor (TGF) $\beta$ production is increased. Then, TGF- $\beta$ inhibits mesangial proliferation and increases ECM secretion, including tenascin [36].
Cast formation can be seen in as many as one-third of LCDD cases [4]. Tubulointerstitial inflammation and fibrosis are the main features of cast formation, with hard and often fractured protein deposits in distal renal tubules (casts), composed of uromodulin and FLCs [37, 38]. Moreover, glomerular capillary walls have deposits of FLCs.

\section{Current treatments and outlook for novel therapies}

The natural course of LCDD is associated with a very poor prognosis, and serum creatinine levels are higher than $1.2 \mathrm{mg} / \mathrm{dL}$ (average $3.9 \mathrm{mg} / \mathrm{dL}$ ) at the diagnosis of LCDD in $97 \%$ of patients at the Mayo Clinic; $39 \%$ of patients developed end-stage renal failure over 34 months of observation, and $32 \%$ of patients died at a mean observation duration of 18 months [21]. The 
combination of multiple myeloma $(\mathrm{RR}=2.75)$ and extrarenal deposition $(R R=2.24)$ are prognostic risk factors [39].

Currently, first-line combination chemotherapy and/ or autologous stem cell transplantation (ASCT) are commonly used treatments [40-42]. However, thalidomide, dexamethasone, bortezomib, lenalidomide and other immunomodulators have not been widely recognized in LCDD, and further studies, especially prospective studies, are needed [2]. Drugs used to treat multiple myeloma are recommended when LCDD patients also have multiple myeloma. In patients with LCDD that is not accompanied by multiple myeloma, haematopoietic stem cell transplantation (HSCT) and chemotherapy with thalidomide, dexamethasone, bortezomib, lenalidomide, and alkylating drugs are recommended [2]. The proteasome inhibitor bortezomib, which directly interferes with and inhibits NF- $\mathrm{kB}$, is a promising drug for reducing the formation of glomerular nodular lesions [43]. Peripheral neuropathy may be induced by both thalidomide and bortezomib because peripheral neuropathy symptoms improved after the end of treatment. It is very important to use adequate drugs to reduce the levels of free light chain. Apart from age, the degree of renal insufficiency at presentation, extrarenal LC deposition and underlying haematopoietic disorders affect patient outcomes [4].

Characteristics and responses to therapy in the included studies are shown in Table 2. A case report was published of a patient with LCDD who responded to MEVP (melphalan + cyclophosphamide + vincristine + prednisolone) chemotherapy, with no nodular glomerular lesions 7 years after MEVP treatment [44]. A complete haematological response, marked with a reduction in proteinuria, and improved renal function were observed in another patient with idiopathic LCDD that was treated with vincristine + dexamethasone (VD) [45].

ASCT is still an effective treatment regimen for LCDD that achieves long-term haematological responses [23, 40, 46]. Lorenz et al. [46] described the outcomes of 6 patients who underwent ASCT, and kidney function and renal response were significantly improved in 4 of the 6 patients with LCDD [46].

After intensive chemotherapy, ASCT can completely alleviate the dysplasia of plasma cells in LCDD [41]. One patient developed uraemia after a median followup of 44 months, but none of the 5 patients who had been treated with chemotherapy + ASCT died [4]. Bortezomib-based induction, followed by a combination of HDM (high-dose melphalan) and ASCT, has been used in several studies. In 2009, bortezomib combined with dexamethasone was used to treat 4 patients with LCDD [47].
Complete haematological responses were achieved in two patients, with serum-free LCs reduced by $>50 \%$ and improved renal function in another two patients. Three patients who underwent HDM+ASCT had complete haematological responses and only microalbuminuria. Non-HDM patients had proteinuria recurrence after 2 months but no haematological recurrence. In 2012, Tovar et al. [24] treated 3 patients with LCDD with bortezomib induction followed by HDM-conditioned ASCT, and 2 of the 3 patients showed rapid and significant improvement in renal function, but the remaining patient still had proteinuria residue. These reports show that the combination of bortezomib and dexamethasone followed by HDM-conditioned ASCT is a well-tolerated and effective treatment strategy for LCDD patients. Therefore, ASCT should be used as an intensifying therapy to achieve a response to chemotherapy induction that is tolerable. In addition, a pregnant patient with LCDD who responded to chemotherapy and ASCT remained in clinical remission with normal serum electrophoresis results at her 1-year follow-up [48].

Dialysis is worth performing in uremic LCDD patients. Uraemia per se does not adversely impact survival, and renal replacement therapy (RRT) is beneficial for patients with LCDD who have achieved uraemic status. Two types of dialysis (peritoneal dialysis and haemodialysis) have similar chances of survival [4].

For some LCDD patients, renal transplantation (RTX) is a good choice after ASCT $[49,50]$. RTX should not be considered if there is persistent disease or no previous treatment to control FLC production. Otherwise, the transplanted kidney will suffer injuries similar to the patient's original kidney $[23,51,52]$. It has been reported that the recurrence rate of LCDD is more than $50 \%$ within 4 years after kidney transplantation and is often associated with transplant failure $[53,54]$. Leung et al. described that LCDD recurred in 5 of 7 kidney transplants [54]. The earliest recurrence of LCDD after RTX was 2.9 months, and the median recurrence time was 33.3 months. Moreover, there was a case report of a triple approach that combined ASCT, RRT, and nonmyeloablative ASCT in a young woman with $\kappa-L C D D$. She was in complete remission for over 9 years, and no immunosuppressive treatment was required [55].

\section{Conclusions}

The present article summarizes that immunofluorescence examination of the kidney is necessary for diagnosis and that MCs are critical in the pathogenesis of glomerulosclerosis. Renal transplantation is a good choice when free light chains production is under control. 


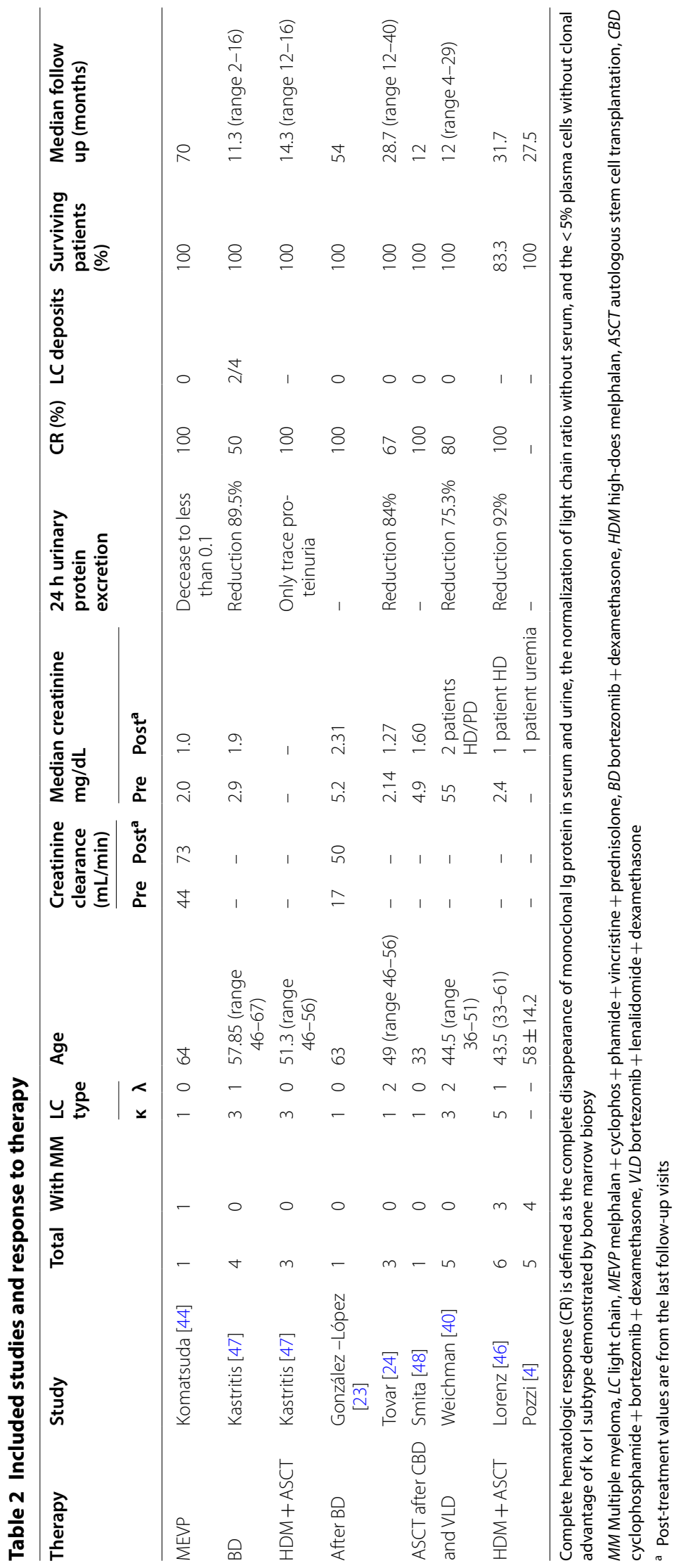




\section{Abbreviations}

LCDD: light chain deposition disease; LCs: light chains; FLCs: free light chains; LM: light microscopy; GBM: glomerular basement membrane; PAS: periodic acid-Schiff; IF: immunofluorescence; EM: electron microscopy; ECM: extracellular matrix; MMPs: matrix metalloproteinases; MCs: mesangial cells; CDR: complementarity-determining region; AA: amino acids; NF-kB: nuclear factor kappa-light-chain-enhancer of activated B cells; PDGF- $\beta$ : platelet-derived growth factor; IL-1: interleukin-1; MCP-1: monocyte chemoattractant protein-1; RANTES: regulated upon activation normal T-expressed and secreted; ICAM-1: intercellular adhesion molecule 1 ; TGF- $\beta$ : transforming growth factor- $\beta$; ASCT: autologous stem cell transplantation; HDM: high-dose melphalan; RTX: renal transplantation; PD: peritoneal dialysis; HD: hemodialysis.

\section{Acknowledgements}

Not applicable.

\section{Authors' contributions}

QW performed the literature search, reviewed articles and wrote the manuscript. FJ reviewed the articles and provided secondary reviews during the manuscript preparation. GX revised the manuscript. All authors read and approved the final manuscript.

\section{Funding}

This work was supported by the National Natural Science Foundation of China (No. 81970583 and No. 81560132). We would like to show my gratitude to the "5511"Innovative Drivers for Talent Teams of Jiangxi Province (No. 20165BCB18018), the Supporting Project for the Foregoers of Main Disciplines of Jiangxi Province (No. 20162BCB22023), and the Natural Science Foundation of Jiangxi Province (No. 20181BAB205016).

\section{Availability of data and materials}

All data generated and analysed during this study are included in this published article.

\section{Ethics approval and consent to participate}

Not applicable.

\section{Consent for publication}

Not applicable.

\section{Competing interests}

The authors declare that they have no competing interests.

\section{Author details}

${ }^{1}$ Department of Nephrology, The Second Affiliated Hospital of Nanchang University, No. 1, Minde Road, Donghu District, Nanchang Zip Code: 330006 , People's Republic of China. ${ }^{2}$ Medical Center of the Graduate School, Nanchang University, Nanchang, China. ${ }^{3}$ Department of Nephrology, People's Hospital of Xinyu City, No. 369, Xinxin North Avenue, High-tech District, Xinyu, People's Republic of China.

Received: 19 May 2019 Accepted: 19 November 2019 Published online: 25 November 2019

\section{References}

1. Sayed RH, Wechalekar AD, Gilbertson JA, et al. Natural history and outcome of light chain deposition disease. Blood. 2015;126:2805-10.

2. Jimenez-Zepeda VH. Light chain deposition disease: novel biological insights and treatment advances. Int J Lab Hematol. 2012;34:347-55.

3. Randall RE, Williamson WC Jr, Mullinax F, et al. Manifestations of systemic light chain deposition. Am J Med. 1976;60:293-9.

4. Pozzi C, D’Amico M, Fogazzi GB, et al. Light chain deposition disease with renal involvement: clinical characteristics and prognostic factors. Am J Kidney Dis. 2003;42:1154-63.
5. Ronco PM, Alyanakian MA, Mougenot B, et al. Light chain deposition disease: a model of glomerulosclerosis defined at the molecular level. Am Soc Nephrol. 2001;12:1558-65.

6. Lin J, Markowitz GS, Valeri AM, et al. Renal monoclonal immunoglobulin deposition disease: the disease spectrum. Am Soc Nephrol. 2001;12:1482-92.

7. Joh K. Pathology of glomerular deposition diseases. Pathol Int. 2007:57:551-65.

8. Von Gise H, Christ H, Bohle A. Early glomerular lesions in amyloidosis. Electronmicroscopic findings. Virchows Arch A Pathol Anat Histol. 1981;390:259-72

9. Herrera GA, Russell WJ, Isaac J, et al. Glomerulopathic light chain-mesangial cell interactions modulate in vitro extracellular matrix remodeling and reproduce mesangiopathic findings documented in vivo. Ultrastruct Pathol. 1999;23:107-26.

10. Herrera GA. Renal manifestations of plasma cell dyscrasias: an appraisal from the patients' bedside to the research laboratory. Ann Diagn Pathol. 2000:4:174-200.

11. Schlondorff D. Roles of the mesangium in glomerular function. Kidney Int. 1996:49:1583-5.

12. VuTH, Werb Z. Matrix metalloproteinases: effectors of development and normal physiology. Genes Dev. 2000;14:2123-33.

13. Parks WC. Matrix metalloproteinases in repair. Wound Repair Regen. 1999;7:423-32

14. Mott JD, Werb Z. Regulation of matrix biology by matrix metalloproteinases. Curr Opin Cell Biol. 2004;16:558-64.

15. Massova I, Kotra LP, Fridman R, et al. Matrix metalloproteinases: structures, evolution, and diversification. FASEB J. 1998;12:1075-95.

16. Van Wart HE, Birkedal-Hansen $\mathrm{H}$. The cysteine switch: a principle of regulation of metalloproteinase activity with potential applicability to the entire matrix metalloproteinase gene family. Proc Natl Acad Sci USA. 1990;87:5578-82

17. Steffensen B, Hakkinen L, Larjava H. Proteolytic events of wound-healingcoordinated interactions among matrix metalloproteinases (MMPs), integrins, and extracellular matrix molecules. Crit Rev Oral Biol Med. 2001;12:373-98.

18. Visse R, Nagase H. Matrix metalloproteinases and tissue inhibitors of metalloproteinases: structure, function, and biochemistry. Circ Res. 2003;92:827-39.

19. Russell WJ, Cardelli J, Harris E, et al. Monoclonal light chain-mesangial cell interactions: early signaling events and subsequent pathologic effects. Lab Invest. 2001;81:689-703.

20. Teng J, Russell WJ, Gu X, et al. Different types of glomerulopathic light chains interact with mesangial cells using a common receptor but exhibit different intracellular trafficking patterns. Lab Invest. 2004;84:440-51.

21. Nasr SH, Valeri AM, Cornell LD, et al. Renal monoclonal immunoglobulin deposition disease: a report of 64 patients from a single institution. Clin J Am Soc Nephrol. 2012;7:231-9.

22. Ronco P, Plaisier E, Mougenot B, et al. Immunoglobulin light (heavy)-chain deposition disease: from molecular medicine to pathophysiology-driven therapy. Clin J Am Soc Nephrol. 2006;1:1342-50.

23. González-López TJ, Vázquez L, Flores T, et al. Long-term reversibility of renal dysfunction associated to light chain deposition disease with bortezomib and dexamethasone and high dose therapy and autologous stem cell transplantation. Clin Pract. 2011;1:e95.

24. Tovar N, Cibeira MT, Rosiñol L, et al. Bortezomib/dexamethasone followed by autologous stem cell transplantation as front line treatment for lightchain deposition disease. Eur J Haematol. 2012;89:340-4.

25. James LC, Jones PC, McCoy A, et al. Beta-edge interactions in a pentadecameric human antibody $\vee$ kappa domain. J Mol Biol. 2007;367:603-8.

26. Cogne' M, Preud'homme JL, Bauwens $M$, et al. Structure of a monoclonal kappa chain of the V kappa IV subgroup in the kidney and plasma cells in light chain deposition disease. J Clin Invest. 1991;87:2186-90.

27. Imai K, Kusakabe M, Sakakura T, et al. Susceptibility of tenascin to degradation by matrix metalloproteinases and serine proteinases. FEBS Lett. 1994;352:216-8.

28. Keeling J, Herrera GA. An in vitro model of light chain deposition disease. Kidney Int. 2009;75:634-45. 
29. Richards SA, Fu J, Romanelli A, et al. Ribosomal S6 kinase 1 (RSK1) activation requires signals dependent on and independent of the MAP kinase ERK. Curr Biol. 1999;9(15):810-20.

30. Herrera GA, Shultz JJ, Soong SJ, et al. Growth factors in monoclonal lightchain-related renal diseases. Hum Pathol. 1994;25:883-92.

31. Mellström K, Heldin CH. Wester mark B: Induction of circular membrane ruffling on human fibroblasts by platelet-derived growth factor. Exp Cell Res. 1988;177:347-59.

32. Rovin $\mathrm{BH}$, Wilmer WA, Danne $\mathrm{M}$, et al. The mitogen-activated protein kinase p38 is necessary for interleukin 1 beta-induced monocyte chemoattractant protein 1 expression by human mesangial cells. Cytokine. 1999;11:118-26.

33. Rovin BH, Dickerson JA, Tan LC, et al. Activation of nuclear factor kappa B correlates with MCP-1 expression by human mesangial cells. Kidney Int. 1995;48:1263-71.

34. Kopp JB, Factor VM, Mozes M, et al. Transgenic mice with increased plasma levels of TGF- $\beta 1$ develop progressive renal disease. Lab Invest. 1996;74:991-1003.

35. Kon A, Vindevoghel L, Kouba DJ, et al. Cooperation between SMAD and NF-kb in growth factor regulated type VII collagen gene expression. Oncogene. 1999;18:1837-44.

36. Giovanni B, Fogazzi MD, Simona Curioni MD, et al. Light-chain deposition disease: its relation with AL-type amyloidosis. Kidney Int. 1984;26:1-9.

37. Pasquali S, Zucchelli P, Casanova S, et al. Renal histological lesions and clinical syndromes in multiple myeloma. Renal Immunopathology Group. Clin Nephrol. 1987;27:222-8.

38. Pirani $C L$, Silva F, D'Agati $\mathrm{V}$, et al. Renal lesions in plasma cell dyscrasias: ultrastructural observations. Am J Kidney Dis. 1987;10:208-21.

39. Paueksakon P, Revelo MP, Horn RG, et al. Monoclonal gammopathy: significance and possible causality in renal disease. Am J Kidney Dis. 2003:42:87-95.

40. Weichman K, Dember LM, Prokaeva T, et al. Clinical and molecular characteristics of patients with non- amyloid light chain deposition disorders, and outcome following treatment with high-dose melphalan and autologous stem cell transplantation. Bone Marrow Transplant. 2006:38(5):339-43.

41. Mariette X, Clauvel JP, Brouet JC, et al. Intensive therapy in AL (amyloidosis and light-chain) deposition disease. Ann Intern Med. 1995;123(7):553.

42. Firkin F, Hill PA, Dwyer K, et al. Reversal of dialysis-dependent renal failure in light-chain deposition disease by autologous peripheral blood stem cell transplantation. Am J Kidney Dis. 2004;44(3):551-5.

43. Adams J, Kauffman M. Development of the proteasome inhibitor Velcade (Bortezomib). Cancer Invest. 2004;22:304-11.
44. Komatsuda A, Wakui H, Ohtani H, et al. Disappearance of nodular mesangial lesions in a patient with light chain nephropathy after long-term chemotherapy. Am J Kidney Dis. 2000;35:E9.

45. Jt SF, Jm M, Ib A, et al. Treatment of idiopathic light chain deposition disease: complete remission with bortezomib and dexamethasone. J Bras Nefrol. 2016;38(4):450-4.

46. Lorenz EC, Gertz MA, Fervenza FC, et al. Long-term outcome of autologous stem cell transplantation in light chain deposition disease. Nephrol Dial Transplant. 2008:23:2052-7.

47. Kastritis E, Migkou M, Gavriatopoulou M, et al. Treatment of light chain deposition disease with bortezomib and dexamethasone. Haematologica. 2009;94:300-2

48. Smita MM, Shibu J, Anup JD, et al. Unmasking and successful management of light chain deposition disease of kidney in pregnancy: a complex case, mirroring the complex needs of pregnancy with kidney disease in India. J Nephrol. 2018;31(5):785-91.

49. Wadhwa NK, Kamra A, Skopicki HA, et al. Reversible left ventricular dysfunction and acute kidney injury in a patient with nonamyloid light chain deposition disease. Clin Nephrol. 2012;78:501-5.

50. Schönland SO, Dreger P, de Witte T, et al. Current status of hematopoietic cell transplantation in the treatment of systemic amyloid light-chain amyloidosis. Bone Marrow Transplant. 2012;47:895-905.

51. Short AK, O'Donoghue DJ, Riad HN, et al. Recurrence of light chain nephropathy in a renal allograft: a case report and review of the literature. Am J Nephrol. 2001;21:237-40.

52. Kaposztas Z, Kahan BD, Katz SM, et al. Bortezomib successfully reverses early recurrence of light-chain deposition disease in a renal allograft: a case report. Transplant Proc. 2009;41:4407-10.

53. Penn I. Occurrence of cancers in immunosuppressed organ transplant recipients. Clin Transpl. 1990;4:53-62.

54. Leung N, Lager DJ, Gertz MA, et al. Long-term outcome of renal transplantation in light-chain deposition disease. Am J Kidney Dis. 2004:43:147-53.

55. Dharshan S, Michael MG, Abdullah MC, et al. Can we cure light chain deposition disease of the kidneys? - A review and case report of a patient treated with a triple transplant approach. Clin Lymphoma Myeloma Leuk. 2016;16(6):95-100.

\section{Publisher's Note}

Springer Nature remains neutral with regard to jurisdictional claims in published maps and institutional affiliations.
Ready to submit your research? Choose BMC and benefit from:

- fast, convenient online submission

- thorough peer review by experienced researchers in your field

- rapid publication on acceptance

- support for research data, including large and complex data types

- gold Open Access which fosters wider collaboration and increased citations

- maximum visibility for your research: over $100 \mathrm{M}$ website views per year

At BMC, research is always in progress.

Learn more biomedcentral.com/submissions 